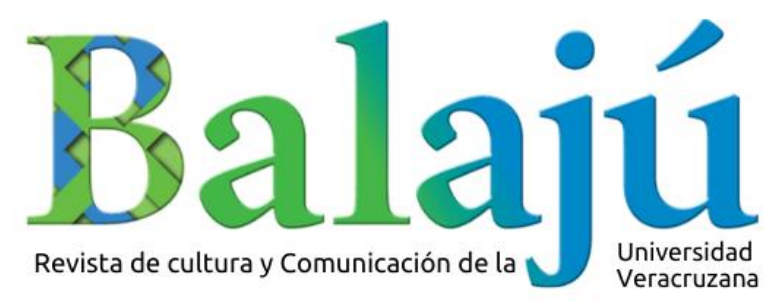

\title{
Melodrama y exceso en el discurso de ficción televisiva: una visión diádica
}

\section{Anderson Lopes da Silva}

Universidad de São Paulo

Recibido: 07-08-2020 | Aceptado: 31-03-2021 


\title{
Balajú
}

\section{Melodrama y exceso en el discurso de ficción televisiva: una visión diádica entre el exclusivismo y la fluidez}

\section{Melodrama and Excess in the Discourse of Television Fiction: A Dyadic Vision between Exclusivism and Fluidity}

\author{
Anderson Lopes da Silva ${ }^{2}$
}

\section{Resumen}

En este artículo se discuten las posibilidades de comprensión del exceso en las teorías narrativas y estilísticas sobre el melodrama y la ficción seriada. La principal estrategia metodológica empleada es la investigación bibliográfica. La centralidad del trabajo se da por la oposicióncomplementariedad entre: 1) el exceso como un modo de la imaginación melodramática; y 2) el exceso como elemento persistente de los modos melodramáticos. Por una visión diádica, el exceso se relaciona como un elemento esencial del melodrama o como una característica relativa al melodrama, pero no exclusivo a él. Se destaca que, a partir de una visión que lo entiende como parte de la estética televisiva y del estilo televisivo, el exceso se coloca como un configurador central de las obras televisivas melodramáticas, no como un elemento que escaparía a la norma del buen gusto y que "excedería" una supuesta y exigida sobriedad.

Palabras clave: Melodrama, ficción televisiva, estilo, estética, exceso.

\begin{abstract}
This article discusses the possibilities of understanding excess in narrative and stylistic theories of serial fiction and melodrama. Using bibliographical research as its primary methodological strategy, it focuses on the opposition-complementarity between: 1) excess as a mode of the melodramatic genre; and 2) excess as a pervasive element of melodramatic modes. Through a dyadic vision, excess is re-read here as either an essential or a relative characteristic of melodrama, yet one that is not exclusive to the genre. It emphasizes that, if we consider excess to be part of the television aesthetic and style, this excess becomes the central configurator of TV drama, rather than an element that escapes the norm of good taste and therefore "exceeds" a supposed and required sobriety.
\end{abstract}

Key words: Melodrama, television fiction, style, aesthetic, excess.

\footnotetext{
${ }^{2}$ Grupo de Investigación en Lenguaje y Discurso en los Medios, Universidad de São Paulo, y Núcleo de Estudios en Audiovisualidad y Ficción Seriada, Universidad Federal de Paraná, Brasil. ORCID: 00000002-4865-4201. Correo: anderlopps@gmail.com.
} 


\section{Balajú}

\section{MELOdRAMA Y EXCESO EN EL DISCURSO DE FICCIÓN TELEVISIVA: UNA VISIÓN DIÁDICA ENTRE EL EXCLUSIVISMO Y LA FLUIDEZ}

Anderson Lopes da Silva

\section{Introducción}

Las relaciones entre exceso y melodrama son, de todas las correlaciones establecidas en este artículo, las más conocidas cuando el tema de las obras de ficción televisiva se pone en discusión. No solo el mundo académico sino, en general, también el público, los críticos y los creadores de contenido entienden tales conexiones como un elemento clave en el proceso de disfrute de estas narrativas. Sobre el tema, Singer (2001: 38-39) recuerda que "los intentos de definir el melodrama pueden tomar algunas direcciones [...] El elemento esencial quizás más relacionado con el melodrama es una cierta cualidad de ‘excitación extrema' o ‘exageración' resumida por el término exceso”. Y, por lo tanto, el exceso melodramático tiende, al menos en un sentido amplio, a ser visto como algo "que [...] apela a lo que existe como más común en el alma y en el gusto de los espectadores" (Thomasseau, 2009: 15).

Lo que se busca en este trabajo es hacer una inmersión epistemológica en la convivencia íntima entre el exceso y el melodrama, para comprender en qué aspectos se acerca o se distancia la fortuna crítica acerca del tema, es decir, cuáles son las visiones que ven esta relación como una e inseparable, de una manera estructural-estructurante o, incluso, de una manera fluida, dominante y modal. Al traer el clásico estudio de Frye (1973) a este debate, es válido señalar que lo que el autor declaró hace décadas todavía resuena en los estudios tradicionales y contemporáneos sobre el melodrama. Para el investigador canadiense, "en el melodrama, dos temas son importantes: la victoria de la virtud moral sobre la villanía y la consecuente idealización de las teorías morales, que se presume, se nutren de la asistencia" (Frye, 1973: 52-53). Entonces, al final, los buenos ganan y los malos son castigados en la relación íntima entre el exceso y el melodrama, ejercida a lo largo de todo el tejido del discurso de ficción televisiva.

Una propuesta teórica similar es la señalada por Thomasseau (2005) para comprender la predilección por esta bipolaridad (especialmente en la búsqueda o en los obstáculos para la realización del bien, de los protagonistas y de sus amores imposibles, etc.). El autor señala que "la [...] persecución mantiene el suspenso; el reconocimiento lo 


\section{Balajú}

elimina brutalmente, y cuanto más rápido ocurre, más patética es la situación" (Thomasseau, 2005: 37). Desde la perspectiva de esta lectura, las conjunciones entre el exceso y el melodrama también encuentran refugio, indirectamente, en otra característica discutida por el autor: la construcción narrativa. Luego, al destacar una tendencia (no un aspecto indiscutible), Thomasseau (2005: 136) expone que la creación artística del melodrama se basa en la afirmación de que "la intriga de un melodrama nunca está bien escrita, pero siempre está bien descrita".

La estructura argumentativa de este artículo se acoge al campo de la literatura académica sobre lo audiovisual al proponer una discusión acerca de las posibilidades de la comprensión del exceso (como elemento estético y estilístico configurador) dentro de las teorías narrativas y discursivas sobre el melodrama y la ficción. Por eso, la centralidad de este trabajo, bajo una mirada diádica, está determinada por la oposicióncomplementariedad entre: 1) el exceso como un modo de la imaginación melodramática (Brooks [1972] 1995); y 2) el exceso como un elemento que permea los modos melodramáticos (Williams ([1991] 2018). Así, la principal estrategia metodológica empleada es la investigación bibliográfica y la tensión teórico-conceptual entre los autores y sus visiones, sin dejar de lado por completo a los autores que dialogan con estas dos matrices diádicas de pensamiento.

A partir de lo que explica Silva (s/f) sobre las posibles relaciones entre melodrama y exceso (mediante una sistematización de las ontologías de naturaleza, composición, propósito y ubicación de las relaciones) es posible entender que Brooks y Williams refuerzan la existencia de una visión diádica entre el carácter exclusivo o fluido del exceso melodramático. Por tanto, la falta de una tercera vía es evidente, sobre todo porque los autores en el campo de los estudios de la televisión influenciados por Brooks o Williams tienden a adherirse a una u otra de las dos visiones presentadas, en un intento de no crear aporías, es decir, obstáculos epistemológicos insuperables o una pseudotercera vía (Silva, $\mathrm{s} / \mathrm{f}) .^{3}$

El criterio para discutir los trabajos de Brooks y Williams se basa en que el pensamiento actual de estos investigadores, a pesar de haber producido sus trabajos seminales en décadas pasadas, sigue siendo voz de relevancia en los análisis contemporáneos, como señalan Zarzosa (2013) y Svartman (2021). Un ejemplo es que,

\footnotetext{
${ }^{3}$ Artículo actualmente en proceso de publicación, que se desprende de la tesis de doctorado del autor.
} 


\section{Balajú}

cuando Svartman (2021) discute la industria televisiva, hace uso de las reflexiones de Brooks como una valiosa consideración, aún hoy en día, para comprender las continuidades y transformaciones actuales por las que atraviesa la telenovela en Brasil. Más que la validez latente de los argumentos aportados por Brooks y por Williams, otro criterio que justifica llevarlos al debate está relacionado con el carácter de aplicabilidad (o la reubicación teórico-metodológica) de sus reflexiones al campo de lo audiovisualtelevisivo, como Martín-Barbero (2009), Capello (2020) y Dorcé (2020) han demostrado ya con éxito.

Cabe destacar que las reflexiones sobre el campo melodramático y el discurso ficcional se producen prolíficamente en la academia latinoamericana (hispanohablante y lusófona), anglófona y francófona; sin embargo, se decidió traer a la discusión las obras clásicas de Brooks y Williams, precisamente, porque no nos interesa aquí que se realicen lecturas hechas por terceros. En lugar de centrarnos únicamente en los artículos de reciente publicación que citan a los dos autores en cuestión, preferimos dirigirnos directamente a las fuentes originales.

\section{Exceso y melodrama: una relación de proximidad}

La idea superficial de que un producto audiovisual sea leído como "cursi", de "mal gusto", sea tratado como "una obra menor" y, por lo tanto, de que no sea "digno" de merecer una reflexión más profunda es frecuentemente asociada al melodrama cuando una perspectiva sobre "televisión de calidad" se plantea como el tema central de una conversación cotidiana (Thorburn, 1976: 595). En el campo de las charlas del día a día, es curioso percibir cómo esa cuestionable presuposición (la "inferioridad" de las obras melodramáticas en la TV) puede ser observada justamente cuando el término "excesivo" entra en escena para justificar la afirmación acerca del juicio sobre el gusto. Esta designación actúa como un adjetivo peyorativo debido a que las telenovelas, miniseries, soap operas y afines, de la televisión abierta, por ejemplo, son entendidas como melodramas "excesivos" en oposición a las obras consideradas más "realistas", "verdaderas", "más sofisticadas" o de "mayor calidad" (como algunas series del prime time televisivo de canales cerrados y plataformas de streaming a menudo son descritas). Por lo tanto, no es muy difícil percibir que uno de los aspectos presentes en la construcción del término excesivo tiene como patrón la sintetización (y eufemización) de 


\section{Balajú}

una cierta visión de calidad que es poco asociada a las producciones referidas como "exageradas", "histriónicas", "hipersensibles", “demasiado conmovedoras" y "emocionalmente embriagadoras".

Es importante destacar cómo la cuestión de clase social (en relación con el poder económico de adquisición de bienes) se muestra muy presente y oportunista al definir/separar productos televisivos considerados como de menor calidad (broadcasting) o de mayor calidad (narrowcasting y microcasting). Es decir, esa es una categorización que tiene, entre otros aspectos, una base cimentada justamente en el acceso o no a una idea (ya desgastada) de "baja" y "alta" cultura como demarcador de diferencia social. Y, por fin, tal categorización está directamente ligada a la popularización y al juicio sobre el gusto por la (sensación de) exclusividad del consumo de determinadas obras. Mucho antes de surgir otros medios como el microcasting de las plataformas de streaming, otra afirmación semejante es presentada por Thorburn (1976: 606) al comentar cómo el carácter popular de la televisión y del melodrama televisivo no se encuadraban como elementos estéticos dignos de apreciación de la crítica justamente porque una cuestión de clase, nuevamente, atravesada por una óptica conservadora, es lo que define qué es de buen gusto y qué no. Por último, el mismo autor recuerda que el melodrama televisivo se ha convertido en un foro público significativamente peculiar, complejo e inmensamente enriquecedor justamente porque su discurso es estéticamente amplio y popular (Thorburn, 1976: 597).

En un camino paralelo a las discusiones del sentido común, muchas veces las reflexiones académicas sobre el melodrama audiovisual también están relacionadas con los términos "exceso" y "excesivo", como parte de un enfoque que no siempre privilegia tal característica como un elemento configurador cualitativo de la obra. Incluso las percepciones sobre la televisión -en cuanto a no ser considerada "lo suficientemente seria"- imposibilitan, no raras veces, discusiones e investigaciones más constantes sobre la peculiaridad de su estética con base en una teoría imagética que la privilegia como un medio narrativo-técnico sui generis (Fahle, 2006:190; Fahle, 2018).

Por otro lado, hay también un escenario innovador de visiones que toman una vía opuesta a una simplista lectura peyorativa del exceso en el melodrama y que puede ser visto en trabajos que relacionan, por ejemplo, los noticieros de televisión y los elementos melodramáticos combinados en la construcción noticiosa (Coutinho, 2012) o, incluso, 


\section{Balajú}

documentales en los que la realidad y variados compromisos afectivos se plantean en conjunción con la imaginación melodramática (Baltar, 2007). Sin embargo, los campos más prolíficos de un pensamiento teórico-práctico sobre exceso y melodrama se encuentran justamente en los estudios de cine (Elsaesser, [1972] 1987; Gledhill, 1987; Landy, 1991; Oroz, 1999; Singer, 2001; Mercer y Shingler, 2013; Gledhill, Williams, 2018) y también en los estudios televisivos sobre la ficción seriada (Ang, 1985; Leal, 1986; Martín-Barbero, [1987] 2009; Mumford, 1995; Allen, 1995; Mattelart y Mattelart, 1998; Huppes, 2000; Balogh, 2002; Lopes, Borelli y Resende, 2002; Mittell, 2004; Mungioli, 2006; Jost, 2007; Rincón, 2007; Fuenzalida, 2007; Sadlier, 2009; Motter, 2009; Esquenazi, 2011; Zarzosa, 2013; Stewart, 2014).

Más que una mera relación de causalidad por sí sola, es posible hablar de cómo la alta productividad del asunto en la literatura académica audiovisual denota un contexto donde melodrama y discursos de ficción son extremadamente relevantes para la aprehensión de los procesos de sentido. Procesos que circundan las realidades culturales y sociales de países e individuos tan diferentes entre sí como los presentados con los autores anteriores.

\section{El exceso como modo en la imaginación melodramática}

En el análisis de obras de autores como Honoré de Balzac y Henry James, el investigador estadounidense Peter Brooks (1995) discute el concepto de imaginación melodramática haciendo un minucioso análisis epistemológico acerca de la definición de melodrama y del contexto histórico que, en cierto modo, lo rodea desde el teatro dramático de la Grecia Antigua. Sin embargo, su enfoque se presenta a partir del "melodrama clásico francés", pasando por la modernización del concepto en el cine y llegando a las telenovelas (y soap operas) de la actualidad que poseen fuertes rasgos en común.

El melodrama, entendido en este trabajo como una de las matrices que forman parte de los procesos de producción de sentido en el discurso de ficción televisiva, también está marcado por visiones y condiciones compuestas que le dieron forma a lo largo de los siglos. Por eso, a primera vista, el adjetivo melodramático puede evocar significados peyorativos. $\mathrm{O}$, como sostienen las fórmulas de los guiones ya realizadas en el melodrama televisivo y en la ficción seriada, el adjetivo melodramático ya denota posiblemente la estructura que se espera de una obra de la teleficción. Es decir, personajes 


\section{Balajú}

bien delineados en sus respectivos caracteres, enfocados en la historia, poca profundidad o densidad de temas, redención o castigo del mal, victoria del bien, entre otras características generalmente previsibles. O, en las palabras del autor, el uso del término melodrama, como un rótulo que trae en sí "mala reputación" y "usos peyorativos", necesita una explicación sobre lo que es el entendimiento presentado como más común sobre el asunto, a saber: "la indulgencia de un fuerte exagero emocional; polarizaciones y esquematizaciones morales; estados extremos del ser, de las situaciones, de las acciones; la villanía evidente, la persecución del bien y la recompensa final por la virtud, expresiones infladas y extravagantes, tramas oscuras, suspenso y cambios asombrosos [en la historia]" (Brooks, 1995: 11-12).

Nuevamente, esa es una visión cristalizada sobre el melodrama televisivo, lo que no quiere decir que todas las múltiples combinaciones de esos reordenamientos narrativos puedan generar siempre la misma "trama estándar". Pero, de igual forma, otra característica esencial del melodrama televisivo es la presencia de la estructura arquetípica del "cuadrilátero melodramático" que lo compone, es decir, en esas narrativas existe la presencia del Justiciero (héroe), del Traidor (villano), de la Víctima (chica dulce) y del Bobo (bufón) como personajes constantes (Martín-Barbero, 2009: 168). Y, a partir de los sentimientos básicos de miedo, entusiasmo, dolor y risa, estos cuatro personajes forman el cuadrilátero melodramático, produciendo así una mezcla de cuatro otros géneros: la novela de acción, la epopeya, la tragedia y la comedia (Martín-Barbero, 2009).

Por otros caminos teóricos (localizaciones geográfica y culturalmente distintas) de los de Martín-Barbero, Brooks (1995) define la imaginación melodramática pensando el melodrama no solo como género, sino como una imaginación transgenérica que sobrepasa barreras de formatos y escuelas, además de transgredir la demarcación entre la alta cultura y el entretenimiento popular. Al entender el drama como una "historia parabólica, excitante y excesiva a partir de cosas banales de la realidad", el autor aproxima mucho su visión acerca de la imaginación melodramática a esta misma definición. Así, el investigador añade la "polarización absoluta de la moralidad" y el "maniqueísmo tácito", además de la idea de una moral oculta y de un modo del exceso como partes del entendimiento de una imaginación melodramática (Brooks, 1995: 4), elementos muy importantes y perceptibles en el modelo de telenovela producido en Brasil y en América Latina. 


\section{Balajú}

Como el modo del exceso es situado y regulado por la moral oculta en la ficción, según Brooks (1995: 5), es significativo observar en las próximas discusiones cuáles son las similitudes y diferenciaciones entre cada uno de estos dos conceptos. Brooks explica que la moral oculta puede ser entendida como la reordenación del mundo moderno (desinteresado por la religión y la ciencia, pero apegado al melodrama y a sus representaciones). Por eso, el "reino de la moral oculta" no es nítidamente visible y necesita ser descubierto, registrado y articulado en el plano real para operar en la “conciencia individual” de las personas (Brooks, 1995: 21). Sería, así, una forma de la "moral de la historia" con la función de "separar lo que puede ser bueno o malo" (Brooks, 1995: 15).

Es importante señalar, como recuerda Dorcé (2020: 3), que la obra de Brooks es vista en el campo de los estudios de la televisión como una obra "canónica" y, por lo tanto, son menos discutidas las visiones dispares a la reflexión que aporta el investigador estadounidense en su comprensión sobre el melodrama. Algunas excepciones se encuentran en los debates desarrollados por Williams $(1991,2018)$-que aquí se opone a la visión exclusivista del exceso como algo intrínseco y solo vinculado al melodrama- y Zarzosa (2013), quien reconfigura la lectura de Brooks para entender el melodrama como una forma de redistribuir la visibilidad del sufrimiento humano y no como el propósito clásico de demostrar la virtud, el bien y el mal.

El principio básico de la moral oculta es reflejar de modo sutil alguna "enseñanza" en el campo ficcional. De ahí que la afirmación de que el melodrama no es solo un drama moralizante sino un "drama de la moralidad” (Brooks, 1995: 20) se vuelve sugestiva para la comprensión de la teleficción, por ejemplo. Es decir que, a través de la moral oculta del melodrama, el orden social es purgado y el imperativo ético logra hacerse claro para la sociedad (Brooks, 1995: 17). En cuanto al modo del exceso en la imaginación melodramática, Brooks afirma que nada escapa a él en el melodrama, ya sea en la dramatización de las palabras y los gestos o en la intensidad y en la polarización de los sentimientos (Brooks, 1995: 4). Nada es innecesario o no "discutible":

El deseo de expresar todo parece ser una característica fundamental de la imaginación melodramática. Nada es limitado porque nada es factible de "no ser dicho"; los personajes están en el escenario para pronunciar lo indecible, se da voz a sus sentimientos más 
profundos, se dramatiza a través de sus intensas y polarizadas palabras y gestos que dan cuenta de toda lección de sus relaciones personales (Brooks, 1995: 4).

Además, un punto de fuerza de la cuestión del exceso en la construcción de la imaginación melodramática se centra en la forma en que la estructura del melodrama es trabajada por el maniqueísmo o, en las palabras de Brooks (1995: 36), un "sentido de confrontación y contraste fundamentalmente bipolar", pues el "mundo según el melodrama es construido bajo un irreductible maniqueísmo [...]. Dilemas melodramáticos y elecciones se construyen en las formas extremas de todo o nada". Es decir, aquí el modo del exceso se manifiesta también por la vía del maniqueísmo como manera de colocar la polarización máxima en escena (sea en la formación de las secuencias escénicas o en la actuación histriónica de algunos actores y actrices). Por tanto, no sorprende que Capello (2020: 10), al utilizar las reflexiones de Brooks, llegue a entender el melodrama, entre otras características, como algo dotado de una "estética abigarrada".

Por esa vía -al conceptualizar la estética del melodrama como "maravillosa", de "extrema sorpresa", "asombrosa" o "impactante" (en una traducción libre de aesthetics of astonishment)-, Peter Brooks destaca la retórica de la narrativa melodramática en lo que se refiere a los usos del lenguaje. Él afirma que las típicas figuras del modo del exceso son las hipérboles, las antítesis y los oxímoron. De estas figuras de lenguaje, las hipérboles se toman como una "forma natural de expresión" de lo melodramático (Brooks, 1995: 40).

Finalmente, el investigador chileno Eduardo Santa Cruz (2002), bajo la influencia de Martín-Barbero, diferencia el modelo brasileño de producción televisiva frente a otros productos televisivos latinos como un modelo modernizante en oposición al mexicano, por ejemplo, considerado como tradicional o clásico. La afirmación de Santa Cruz, sin embargo, sugiere que las tramas modernas o clásicas, sin diferencia, se muestran como el espacio perfecto para la ocurrencia del modo del exceso.

\section{El exceso como elemento persistente de los modos melodramáticos}

La discusión desarrollada por Linda Williams (2018) reconoce de modo importante los trabajos de Peter Brooks, Thomas Elsaesser y Ben Singer (nominalmente citados) a partir de la herencia y de la relevancia de las investigaciones de esos autores para el campo del 


\section{Balajú}

género melodramático dentro de lo audiovisual. Sin embargo, es Christine Gledhill el nombre más reverenciado en el discurso de Williams, justamente porque, según ella, Gledhill da un paso adelante en la discusión sobre el entendimiento del melodrama. Ella no comprende el melodrama como un género fijo, sino como algo dotado de cierta fluidez, modulación, permeabilidad, capaz de transformar y de "contaminar" varios otros géneros que, en principio, nunca serían considerados como hechos de una melodramaticidad, porque se ven como obras "clásicas" y "realistas" (Williams, 2018: 211). Es justamente a partir de la autora británica que Williams amplía la comprensión del exceso en los estudios sobre el melodrama y lo audiovisual como algo que necesita ser visto desde la óptica de la fluidez y de la contaminación recíproca, entre otros géneros y formatos narrativos posibles.

Un punto interesante -y en común acuerdo con el discurso aportado por Brookses lo que Williams (2018: 207) señala como la percepción histórica de mirar el exceso del melodrama como algo desagradable y en oposición a la idea de buen gusto o de moderación en las producciones y expresiones audiovisuales (esencialmente cinematográficas, en el caso de la cita de la autora). En otras palabras, el exceso del melodrama es comparado contrariamente a una idea de pérdida de proporción (Williams, 2018: 207). Pero ¿cuál es el punto de referencia establecido para comprender una producción como "excesivamente" melodramática (luego, desproporcional) en relación con el mundo de la sobriedad y de la calidad artística?

La respuesta dada por la investigadora estadounidense es que el melodrama es el "chivo expiatorio" justamente porque en él se asigna todo aquello que aparenta ser ilegítimo, anticuado y agotador (Williams, 2018: 213-214). Y, en el caso de las investigaciones pioneras de Gledhill (1987) y Mumford (1995), es notoriamente claro que las relaciones de género atraviesan, en gran medida, esa construcción de demérito en relación con las producciones melodramáticas, ya que ellas fueron vistas por mucho tempo -en un raciocinio susceptible de ser cuestionado hoy- como obras dirigidas mayoritariamente al público femenino, al ambiente doméstico, al espacio de la ausencia de reflexión y puramente entendidas como objetos de alienación y de entretenimiento barato para las mujeres. Y, aunque la autora no entre en el tema del mérito de la cuestión, no es absurdo proponer una reflexión -ya enseñada por Martín-Barbero (2009) y MartínBarbero y Germán Rey (2001)- sobre cómo una justificación posible para ese carácter 


\section{Balajú}

"anticuado" dado al melodrama tiene que ver con las relaciones de clase involucradas en el proceso de construcción de las audiencias y de sus gramáticas televisivas en la comprensión de las obras. Y ahí, de manera análoga, el exceso (por la vía de las "lágrimas femeninas" o del "chasco y risas populares") ciertamente encuentra guarida como un elemento de desagravio contrario al intelecto, al buen gusto y a todo lo que es comedido (y, por consiguiente, como algo sin calidad).

Aquí es necesario señalar el contexto cultural como uno de los escenarios que más importan cuando cuestiones como "excesivo" versus "comedido" aparecen alrededor del melodrama -y de las emociones suscitadas por él- en las más variadas culturas. Las representaciones de estas distinciones (especialmente en la dicotomía Occidente versus Oriente) pueden ser vistas en las discusiones indicadas por Ira Bhaskar (2018), en la cultura india, y Panpan Yang (2018), en la cultura china. En ambas discusiones, el exceso permanece como un elemento vinculado al melodrama, sin embargo, con remodelaciones a partir del "color local" desde donde se miran los objetos audiovisuales.

Sin embargo, el centro de la argumentación postulada por Williams está en la comprensión del exceso como un elemento estético que permea los modos melodramáticos. La autora arroja luz sobre la discusión al presentar el melodrama ya no entendido como un género, sino bajo otra óptica, en la cual propone pensar en modos de melodrama (Williams, 2018: 214), modos que pueden estar presentes en otras obras, en otras producciones y en otros géneros que, en un primer momento, pudieran "no dialogar" tan tradicionalmente con el melodrama. Por lo tanto, sería posible comprender modos de melodrama que enfatizarían ya sea el pathos, la acción o incluso las sensaciones de represión y de sublimación en narrativas infinitamente diferentes entre sí. Esto demuestra cómo el carácter demoledor y modular del exceso es inherente también a un entendimiento del melodrama no solo como un rígido conjunto de elementos que lo configuran como un género stricto sensu de carácter distintivo o exclusivo de otros géneros.

La persistencia del exceso y las modulaciones posibles del melodrama reubican la discusión para entender cómo cualquier tipo de obra, producción y género puede inmiscuirse, contaminarse e interactuar con el exceso en los más variados niveles. Por ese camino, es posible decir que los modos melodramáticos están atravesados por el exceso pero, en sí mismos, ellos no son el excedente esencial (Williams, 2018: 214). En este 


\section{Balajú}

sentido, la autora va al contrario de los estudios académicos que ven casi siempre el melodrama como inherentemente excesivo.

Y, en ese punto, Williams critica directamente a Brooks al comentar que la lectura del autor -acerca de que la imaginación melodramática contiene inalienablemente el "modo del exceso" en sí- es una de las mayores contribuciones para el mantenimiento de ese pensamiento, según ella, problemático. Por eso, Williams (2018: 22) afirma que todavía existe una "tendencia a ver el melodrama como algo viejo y regresivo, en vez de un medio envolvente y que sigue relativamente nuevo" (Williams, 2018: 212), lo que tal vez haga pasar desapercibido la calidad de buenos melodramas televisivos, como afirma la investigadora (Williams, 2018: 216), que ahora ya no necesitan recurrir siempre al famoso "final feliz" dada la complejidad de sus producciones, especialmente, formatos de larga duración que permiten un trabajo más profundo en la construcción de los personajes y de los arcos dramáticos.

Un debate productivo puede ser puesto en cuestión si se tiene en cuenta cómo la temporalidad elástica y la duración de las obras promueven nuevos reordenamientos narrativos a las producciones melodramáticas más contemporáneas en relación con el exceso presente en ficciones seriadas más antiguas. En ese sentido, en contraposición con la afirmación de Williams, vale destacar la afirmación -escrita más de 40 años antes- del investigador estadounidense D. Thorburn (1976) acerca de una "pequeña" complejidad de las narrativas melodramáticas de la televisión de entonces. Él comenta esto al decir que, por excelencia, el melodrama televisivo trata del banal y del ordinario encontrado en el real; sin embargo, su forma de representar moral y emocionalmente lo ordinario está fuera del "mundo real" (en gran virtud) por la presencia del exceso, como un elemento motivador de ese aumento en el abordaje de lo ordinario (Thorburn, 1976: 603). Es decir, melodrama y nuevas temporalidades narrativas parecen estar bien entrelazados como factores que determinan la alta o baja complejidad del producto televisivo y la visión -de demérito o no- de la presencia del exceso en estas (según, por supuesto, el periodo sociohistórico desde donde se hace la observación).

Ben Singer (2001), aunque no es citado por Williams, posiblemente encajaría en esa crítica, ya que su lectura acerca del melodrama también está relacionada con el entendimiento de este término (exceso) como algo de extrema emoción y sentimentalismo. Tomando como partida la visión de Brooks, Singer comenta que "el 


\section{Balajú}

melodrama supera la represión, al dar una plena expresión a las pasiones ampliadas, las intensidades de amor y de odio profundo (o no tan profundo) que residen dentro de todos nosotros" (Singer, 2001: 51).

En contraposición con la idea del exceso como algo que puede ser desechado (el "excedido") en función de una "sobriedad" o de algo "idealizado sin exceso", Williams (2018) apunta, ahora, una noción de exceso como concepto estético pulverizado en varios usos y momentos de una misma obra también (además de la posibilidad de estar presente en otras obras, géneros y formatos distintos). Así, además de pensar el exceso como un concepto aprehendido y restringido solamente a narrativas que dialogan directamente con los géneros del cuerpo ${ }^{4}$ (melodrama, horror y pornografía), como anteriormente señalaba Williams (1991), una nueva óptica de comprensión sobre el término surge y lo desplaza hacia un sesgo estetizante. Este sesgo se refiere a una lectura del concepto en la cual este puede proponer modulaciones eficaces del exceso por medio de intensidades y repeticiones distintas. Un exceso que puede ser encontrado con modulaciones pulverizadas y variables en otros discursos y géneros, y no únicamente en la tríada inicial mencionada por Williams (1991).

Es posible relacionar el discurso de Williams con las discusiones de Thorburn (1976) y Smit (2010) sobre cómo las ficciones televisivas "serias", cuando necesitan ser entendidas o leídas por la crítica y el público como producciones de calidad, necesitan distanciarse de la etiqueta del "melodrama" o de lo "melodramático". Ejemplos de ello son las críticas que asociaron (con intención peyorativa) las series Game of Thrones (HBO, 2011-2019), Little Fires Everywhere (Hulu/Amazon Prime Video, 2020) y Tiny Pretty Things (Netflix, 2020) a la idea de que sus tramas eran similares a las telenovelas. Sobre Game of Thrones, una de las críticas dice que uno de los mayores absurdos de la trama fue "dar un adiós bastante melodramático a la madre de los dragones (Daenerys)" al final de la serie y, en el mismo tono: “obviamente, ningún amante de la serie esperaba, por ejemplo, por un final como el de las telenovelas, llenos de bodas y esos clichés, tan

\footnotetext{
${ }^{4}$ Según Baltar (2012: 127): "El término 'géneros del cuerpo' es en realidad una formulación de Carol Clover para el tipo de relación que se establece entre obra y público en el género del horror y en el de la pornografia". Williams lo toma prestado y lo amplía para incluir también el melodrama, pues entiende que la movilización característica de ese género es una doble articulación del exceso en términos de éxtasis y de espectáculo. Así, aunque no excluye la posibilidad de que otros géneros también sean pensados como "del cuerpo" (como el musical y cierto tipo de comedia), Williams, en un artículo de 1991, abordó los aspectos estilísticos y políticos de ese elemento, usado de modo estructurante, común a los tres géneros (melodrama, terror y pornografía).
} 


\section{Balajú}

repetidos también en las películas de Hollywood" (Monteiro, 2019). En relación con Little Fires Everywhere, el propio título de una crítica ya anticipa la visión descalificadora que se tiene de la obra, asociada al melodrama: "Little Fires Everywhere: los clichés de la telenovela que arruinaron un buen material" (Pereira, 2020). Al identificar la premisa de Tiny Pretty Things como melodramática, la crítica incluso caracteriza la obra como "hipnóticamente mala" (Canhisares, 2021). En este sentido, al comentar series como Nip/Tuck (FX, 2003-2010) y Dexter (Showtime, 2006-2013), Smit afirma que:

La presión para que estas series demuestren calidad y sofisticación también significa que es relevante para ellas adoptar un [modo de] enfoque irónico que las rescata de ser vistas inicialmente como "melodramas ingenuos". Esto no significa, sin embargo, que estas series sacrifiquen un cierto tipo de placer en función de la sensación, la emoción y el exceso asociados al modo melodramático (Smit, 2010: 155).

Así, al desplazar la esencialización inherente del exceso como algo siempre unido al melodrama, es posible percibir que los modos melodramáticos pueden participar de otros campos audiovisuales y transitar por otros modos, por ejemplo, más realistas o más cómicos (Williams, 2018: 214). Aun al dejar de lado el carácter esencialista, las ideas de exceso como elemento perdurable y de melodrama como modo no abandonan del todo el carácter moralizante del melodrama propuesto por Brooks en la discusión ya presentada anteriormente en cuanto a la discusión de la imaginación melodramática y de la moral oculta. Es ahí quizás que tanto Williams como Brooks parecen encontrarse nuevamente en acuerdos potencialmente compatibles al ver en la moralidad una característica esencial para pensar la relevancia del melodrama para las sociedades que lo vivencian de manera ficcional: "Melodrama es la forma en que los problemas sociales y las controversias de cada época pueden ser abordados [...]. El melodrama es un aliado de los sueños de revolución [...] El melodrama ha estado al lado de los oprimidos, y por eso parece también estar al lado de los cambios sociales e incluso de las revoluciones" (Williams, 2018: 215).

Por eso, categóricamente, la autora encierra su discusión de manera nítida al dejar clara su posición en el entendimiento de que "ni la música exagerada (excesiva) ni la derrota del mal por el bien es esencial para el melodrama". En verdad: "Lo que es esencial, yo afirmo, es el reconocimiento dramático del bien y del mal y que, al tomar conciencia de ello, hay al menos la esperanza de que la justicia pueda ser alcanzada" (Williams, 


\section{Balajú}

2018: 215). Es decir, es posible encontrar en Williams más afinidad entre su obra y la de Brooks a partir de la moral oculta, que propiamente en la lectura del modo del exceso o de la estética del asombro (aesthetics of astonishment). Sin embargo, es posible reflexionar que para Brooks la discusión de la moral oculta es fuertemente llevada al campo de la orientación de una moral que dirija los saberes y las acciones acerca del bien y del mal en un mundo que necesita de (un supuesto) orden en el caos que es la vida social. Y, por otra vía (quizás) más emancipadora, se ve que Williams entiende la moral del melodrama como una perspectiva que denota potencialmente usos sociales y apropiaciones de lectura de la audiencia sobre el mundo ficcional hacia el mundo real, a fin de desestructurar el statu quo de un determinado tiempo-espacio de vida.

\section{Conclusiones}

Más que contraponer dos visiones diametralmente opuestas sobre el entendimiento de exceso y melodrama en el contexto del discurso de ficción televisiva, lo que este trabajo intentó generar fue una reflexión que señala cómo la lectura diádica propuesta por Brooks (1995) y Williams (2018) puede ser útil según el punto de vista desde el cual se elige trabajar el objeto analizado. En otros términos, si la opción por pensar el exceso en Brooks es resaltada, se debe considerar que el centro de las discusiones presupone pensar el exceso como un elemento incluido en la imaginación melodramática, algo inherente a ella y en común diálogo de dependencia con la moral oculta y la estética del asombro, también trabajadas por el autor. Si la mirada teórica decide tomar el camino de las afirmaciones de Williams, el entendimiento de exceso y melodrama debe flexibilizarse al punto de comprender que los dos (exceso y melodrama) pueden actuar juntos (como elementos intercambiables), pero no hay una jerarquía conceptual que demuestre pertenencia exclusivista entre el uno y el otro; es decir, el exceso como elemento endémico y el melodrama como modo ya denotan la posibilidad de examinar zonas intercambiables de formatos, zonas de contactos entre los géneros, otros modos y otra infinidad de lecturas en el campo audiovisual.

Sin embargo, en ambos casos, el melodrama no es visto como un mero género. En el caso de Brooks, lo que se presenta es la imaginación melodramática (en la lógica de un melodrama considerado como transgenérico) y para Williams surge la idea de modo melodramático, o sea, algo aún más fluido, más y más penetrante como una modulación 


\section{Balajú}

nada esencialista, pero potencialmente muy circulante en los procesos de aprehensión de las producciones de sentido.

En ese sentido, la lectura emprendida aquí (y pensada, particularmente, a partir de Brooks y de Williams) tiene como tesis que el exceso no debe ser considerado como categoría contraria a la "buena medida" (al "comedido" buen gusto) en comparación superficial con otras producciones consideradas como "menos excesivas" y, por lo tanto, mejor acabadas o sofisticadas. En este caso, el exceso puede (y precisa) ser leído como elemento composicional de la estética y de la estilística de las obras melodramáticas (ya sea por la vía de comprenderlo como un "modo del exceso" preponderante, fundacional, inalienable e inherente de la "imaginación melodramática" o también por la comprensión de los "modos melodramáticos" permeados por la "persistencia del exceso" que no se restringe pura y solamente al melodrama, y que puede encontrar en este un espacio prolífico de producción de sentido).

Como un aporte, es posible destacar que el exceso, a partir de una visión que lo entienda como parte importante de la estética y del estilo televisivo, puede ser visto como constituyente central de las obras televisivas melodramáticas (exclusivista o fluido, a partir del punto de vista desde el cual se mira). Es decir, no como un elemento que escaparía a la norma del buen gusto o que "excedería" una supuesta y exigida sobriedad, sino que el exceso sería reubicado aquí como una característica cualitativa del acabado estético formal de tales obras. Además, un punto que merece destacarse en este espacio es el poder reflexivo y analítico que todavía ofrecen las obras de Brooks y de Williams, cada una en su propio contexto, en nuestros días. En otras palabras, los estudios de la década de 1970 de Brooks y los estudios de la década de 1990 de Williams continúan reverberando sus concepciones diádicas por parte de autores que analizan obras de estas dos primeras décadas de los años 2000, como es el caso ya mencionado de Zarzosa (2013), Dorcé (2020), Capello (2020), Svartman (2021) y otros más.

Por último, la lectura del exceso necesita ser retratada como una característica cualitativa del melodrama y no como un elemento definidor de una presunta ausencia de calidad. ¿Por qué? Porque el exceso no es un demérito. Por el contrario, el exceso, cuando es analizado en el contexto del melodrama televisivo, puede ser una referencia teórica, ontológica, epistémica, metodológica y analítica que indica un rasgo estético indeleble de las matrices constituyentes del ser melodramático de una producción. Estos rasgos son 


\section{Balajú}

fuertemente aprehensibles empíricamente, desde la viñeta de apertura hasta la construcción de los personajes, de secuencias escénicas, de los leitmotive, de la mise-enscène hasta la mise en phase televisiva de una obra melodramática. Es decir: no importa si el melodrama es entendido como imaginación o como modo: el exceso -además de un mero juicio de gusto- es parte simbiótica de su composición y merece ser examinado como tal.

\section{Referencias}

ALLEN, R. (1995). To Be Continued... Soap Operas around the World. Nueva York y Londres: Routledge.

ANG, I. (1985). Watching Dallas: Soap Opera and the Melodramatic Imagination. Londres: Methuen.

BALOGH, A. (2002). O discurso ficcional na TV: sedução e sonho em doses homeopáticas. São Paulo: EDUSP.

BALTAR, M. (2007). Realidade lacrimosa: diálogos entre o universo do documentário e a imaginação melodramática. Tesis de doctorado, Programa de Posgrado en Comunicación. Niterói, RJ: Universidade Federal Fluminense.

BALTAR, M. (2012). "Tessituras do excesso: notas iniciais sobre o conceito e suas implicações tomando por base um Procedimento operacional padrão". Significação: Revista de Cultura Audiovisual 39(38), 124-146, https://doi.org/10.11606/issn.2316-7114.sig.2012.71141.

BHASKAR, I. (2018). "Expressionist Aurality. The Stylized Aesthetic of Bhava in Indian Melodrama”. En C. Gledhill \& L. Williams (eds.), Melodrama Unbound: Across History, Media, and National Cultures, pp. 253-272. New York: Columbia University Press.

BROOKS, P. ([1972] 1995). The Melodramatic Imagination: Balzac, Henry James, Melodrama, and the Mode of Excess. New Haven y Londres: Yale University Press.

BUTLER, J. (2010). Television Style. Nueva York y Londres: Routledge.

CANHISARES, M. (2021). Crítica: O Preço da Perfeição, la. temporada. Omelete, https://www.omelete.com.br/netflix/criticas/o-preco-da-perfeicao-1a-temporada (fecha de acceso: 10/02/21). 
CAPPELLO, G. (2020). "El melodrama como pulso esencial. Una mirada desde la narrativa serial". Comunicación y Sociedad 17, 1-23. https://doi.org/10.32870/cys.v2020.7491.

COUTINHO, I. (2012). Dramaturgia do telejornalismo: a narrativa da informação em rede e nas emissoras de televisão de Juiz de Fora-MG. Rio de Janeiro: Mauad X.

DORCÉ, A. (2020). "Escenarios emergentes del melodrama en el paisaje audiovisual contemporáneo". Comunicación y Sociedad e7501, 1-18. https://doi.org/10.32870/cys.v2020.7501

ELSAESSER, T. (1987). "Tales of Sound and Fury: Observations on the Family Melodrama”. En C. Gledhill, Home is Where the Heart Is: Studies in Melodrama and the Woman's Film, pp. 43-69. Londres: BFI.

ESQUENAZI, J. (2011). As séries televisivas. Lisboa: Texto \& Grafia.

FAHLE, O. (2006). "Estética da televisão: passo rumo a uma teoria da imagem da televisão". En C. Guimarães, B. Leal y C. Mendonça, Comunicação e experiência estética, pp. 190-208. Belo Horizonte: UFMG.

FAHLE, O. (2018). "Prefácio". En F. Muanis, A imagem televisiva: autorreferência, temporalidade, imersão, pp. 15-17. Curitiba: Appris.

FRYE, N. (1973). Anatomia da Crítica. São Paulo: Cultrix.

FUENZALIDA, V. (2007). “Audiencias televisivas y consumo cultural”. En E. Pirard y N. Rampaphorn (eds.), Televisión y cultura, una relación posible, pp. 89-94. Santiago: Lom/Consejo Nacional de la Cultura y las Artes.

GLEDHILL, C. (1987). Home Is Where the Heart Is: Studies in Melodrama and the Woman's Film. Londres: British Film Institute.

HUPPES, I. (2000). Melodrama: o gênero e sua permanência. São Paulo: Ateliê Editorial.

JOST, F. (2007). Compreender a televisão. Porto Alegre: Sulina.

LANDY, M. (1991). Imitations of Life: A Reader on Film and Television Melodrama. Detroit: Wayne State University Press.

LEAL, O. (1986). F. Leitura Social da Novela das Oito. Petrópolis: Vozes.

LOPES, M. I. V.; BORELLI, S. H. S.; y V. R. RESENDE, V. R. (2002). Vivendo com a telenovela: mediações, recepção, teleficcionalidade. São Paulo: Summus Editorial. 


\section{Balajú}

MARTÍN-BARBERO, J. (2009). Dos meios às mediações: comunicação, cultura e hegemonia. Rio de Janeiro: UFRJ.

MARTÍN-BARBERO, J. y G. REY. (2001). Os exercícios do ver: hegemonia audiovisual e ficção televisiva. São Paulo: Senac.

MATTELART, M. y A. MATTELART (1998). O carnaval das imagens: a ficção na TV. São Paulo: Brasiliense.

MERCER, J. y M. Shingler (2013). Melodrama: Genre, Style, and Sensibility. Nueva York: Columbia University Press.

MITTELL, J. (2004). Genre and television. Nueva York: Routledge.

MONTEIRO, R. (2019). "Os cinco momentos mais absurdos do final de Game of Thrones". GQ, https://gq.globo.com/Cultura/noticia/2019/05/os-5-momentosmais-absurdos-do-final-de-game-thrones.html (fecha de acceso: 10/02/2021).

MOTTER, M. (2009). Teledramaturgia: agente estratégico na construção da TV aberta brasileira. São Paulo: INTERCOM.

MUANIS, F. (2018). A imagem televisiva: autorreferência, temporalidade, imersão. Curitiba: Appris.

MUNGIOLI, M. C. P. (2006). Minissérie Grande Sertão Veredas: Gêneros e TemasConstruindo um Sentido Identitário de Nação. Tesis de doctorado en Ciencias de la Comunicación, Escuela de Comunicaciones y Artes, Universidade de São Paulo, São Paulo.

MUMFORD, L. (1995). Love and Ideology in the Afternoon: Soap Opera, Women, and Television Genre. Bloomington: Indiana University Press.

OROZ, S. (1999). Melodrama: o Cinema de Lágrimas da América Latina. Rio de Janeiro: Funarte.

PEREIRA, I. (2020). "Little Fires Everywhere: clichês de novela atrapalham bom material". Cineset, https://www.cineset.com.br/critica-little-fires-everywherereese-witherspoon/ (fecha de acceso: 10/02/2021).

RINCÓN, O. (2007). “Televisión e identidades: hacia una construcción (+) diversa de la realidad". En E. Pirard y N. Rampaphorn (eds.), Televisión y cultura, una relación posible, pp. 25-43. Santiago: Lom Ediciones/Consejo Nacional de la Cultura y las Artes.

ROCHA, S. (ed.) (2016). Estilo televisivo e sua pertinência para a TV como prática cultural. Florianópolis: Insular. 


\section{Balajú}

SADLIER, D. (2009). Latin American Melodrama: Passion, Pathos, and Entertainment. Chicago: University of Illinois Press.

SANTA CRUZ, E. (2003). Las telenovelas puertas adentro: el discurso social de la telenovela chilena. Santiago: Lom.

SILVA, A. L. (s/f). Melodrama, excesso e narrativas midiáticas: uma sistematização baseada na abordagem de "parentesco intelectual". Avance de investigación, inédito.

SINGER, B. (2001). Melodrama and Modernity: Early Sensational Cinema and Its Contexts. Nueva York: Columbia University Press.

SMIT, A. J. (2010). Broadcasting the Body: Affect, Embodiment and Bodily Excess on Contemporary Television. Ph.D. Dissertation (Film and Television Studies), University of Glasgow, Glasgow, UK.

STEWART, M. (2014). Melodrama in Contemporary Film and Television. Londres: Palgrave Macmillan.

SVARTMAN, R. (2021). Telenovelas and Transformation: Saving Brazil's Television Industry. Nueva York y Londres: Routledge.

THOMASSEAU, J. M. (2005). O melodrama. São Paulo: Perspectiva.

THOMASSEAU, J. M. (2009). Mélodramatiques. Vincennes: Presses Universitaires de Vincennes.

THORBURN, D. (1976). “Television Melodrama”. En H. Newcomb (ed.), Television: The Critical View, pp. 595-608. Nueva York: Oxford University Press.

WILLIAMS, L. ([1991] 2018). "Film Bodies: Gender, Genre, and Excess". Film Quarterly 44(4), 2-13, https://doi.org/10.2307/1212758.

WILLIAMS, L. (2018). "Tales of Sound and Fury... or, the Elephant of Melodrama”. En C. Gledhill y L. Williams (eds.), Melodrama Unbound: Across History, Media, and National Cultures, pp. 205-217. Nueva York: Columbia University Press.

YANG, P. (2018). "Repositioning Excess: Romantic Melodrama's Journey from Hollywood to China”. En C. Gledhill y L. Williams (eds.), Melodrama Unbound: Across History, Media, and National Cultures, pp. 219-236. Nueva York: Columbia University Press.

ZARZOSA, A. (2013). Refiguring Melodrama in Film and Television: Captive Affects, Elastic Sufferings, Vicarious Objects. Lanham, MD: Lexington Books. 